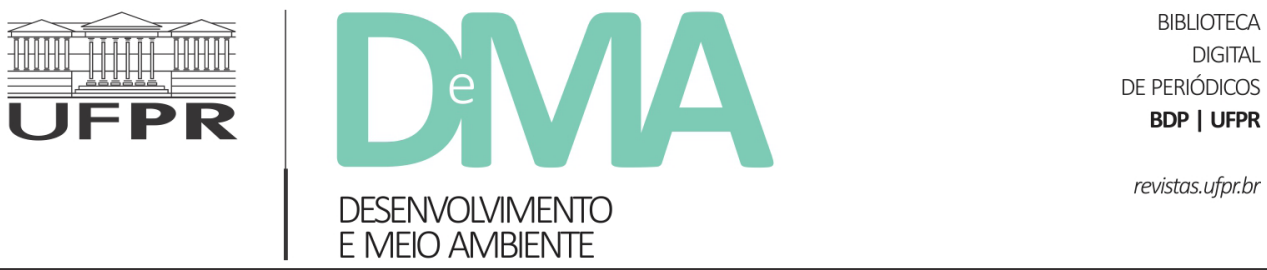

\title{
Indicador qualitativo de tensões no uso das águas em identidades territoriais de vida rural e urbana: evidências empíricas na Região Metropolitana de Salvador, Bahia (Brasil)
}

\section{Qualitative indicator of tensions in water use in territorial identities of rural and urban life: empirical evidence in the Metropolitan Region of Salvador, Bahia (Brazil)}

\begin{abstract}
Débora Carol Luz da PORCIUNCULA ${ }^{1}$, Manuel Vitor Portugal GONÇALVES ${ }^{1 *}$, Cristina Maria Macêdo de ALENCAR $^{1}$

${ }^{1}$ Programa de Pós-Graduação em Território, Ambiente e Sociedade, Universidade Católica do Salvador (UCSAL), Salvador, BA, Brasil.

*E-mail de contato: hidrovitor81@gmail.com
\end{abstract}

Artigo recebido em 27 de outubro de 2019, versão final aceita em 19 de outubro de 2020, publicado em 10 de agosto de 2021.

\begin{abstract}
RESUMO: Este artigo almejou compreender a distribuição das evidências empíricas que tencionam os modos de vida rural e urbano na relação com o uso das águas e identidades territoriais na Região Metropolitana de Salvador (RMS), Bahia, Brasil. Foi desenvolvida uma metodologia para a identificação de tensões territoriais, observadas de 2005 a 2015, no tocante à disputa pelo uso das águas na RMS, denominada de Indicadores Qualitativos de Tensão no Uso das Águas (IQTA). A utilização da IQTA permitiu a identificação de evidências e categorização de tensões no uso da água na RMS, ou seja, categorias metodológicas interpretativas e analíticas de eventos empíricos, de modo a lhes atribuir conteúdo de fenômeno e, a partir daí, tipificá-los. Obteve-se uma predominância da tensão pela apropriação da água (T-1), em especial nas áreas de maior demanda por água para usos urbano-industriais. A tensão dos usos da água em atividades culturais (T-3), a menos frequente, confirmou a permanência contra-hegemônica da ruralidade no espaço metropolitano e revelou um nítido potencial para o desenvolvimento humano e conservação da natureza, porque tais usos demandam por boas condições ambientais dos mananciais. A aplicação do IQTA deslindou uma dimensão da realidade social, que emergiu das noções de rural e ruralidade metropolitana em sua relação com o uso das águas, ignorada nas políticas públicas da RMS, cuja questão ambiental poderia ser ressignificada no espaço da metrópole como rural-urbana.
\end{abstract}

Palavras-chave: tensões; usos da natureza; rural-urbano; desenvolvimento; identidades territoriais; civilidade metropolitana. 
ABSTRACT: The objective of this paper is to understand the distribution of the empirical evidence that intends rural and urban ways of life in relation to the use of waters and territorial identities in the Metropolitan Region of Salvador (MRS), Bahia, Brazil. A methodology based on the identification of territorial tensions, observed from 2005 to 2015, regarding the dispute over water use in the MRS, called Qualitative Indicators of Water Use Tension (QIWT). The use of QIWT allowed the identification of evidences and categorization of tensions in the use of water in the MRS, that is, interpretative and analytical methodological categories of empirical events in order to assign them phenomenon content and from then on to typify them. There was a predominance of tension by the appropriation of water (T-1), especially in the areas of greater demand for water for urban-industrial uses. The tension of the uses of water in cultural activities (T-3), the least frequent, confirmed the permanence counterhegemonic the rural in the metropolitan space and revealed a clear potential for human development and nature conservation, because such uses demand good environmental conditions of the springs and sources of water supply. The application of the QIWT revealed a dimension of social reality, which emerged from the notions of rural and metropolitan rurality in its relationship with the use of water, ignored in the public policies of the MRS, whose environmental issue could be re-signified in the space of the metropolis as rural-urban.

Keywords: tensions; uses of nature; rural-urban; territorial identities; development; metropolitan civility.

\section{Introdução}

As tensões e os conflitos territoriais pela apropriação e uso das águas doces é uma realidade vivenciada em muitos países e regiões, quer pelo quadro histórico de escassez de águas doces quer pelas rigorosas condições geoclimáticas quer pela abundância hídrica contrastante com poluição decorrente do ritmo e intensidade com que o processo de produção socioespacial se desenvolve, consome e degrada a natureza; quer pela ineficiência e ineficácia que caracteriza a gestão da água em muitas regiões e países pobres e ricos (Castro, 2007; 2019). Este é um fenômeno inerente ao modo de produção capitalista, em que, contraditoriamente, a natureza é apropriada, consumida e degradada, após ser transformada na categoria mais geral do capitalismo, a mercadoria. No entanto, assinala Castro (2016, p. 1) que a condição de mercantilização da água é limitada "devido ao caráter lento e fragmentado do processo de racionalização de controle da água e de sua gestão". O Brasil possui as duas conflitualidades e apresenta as mesmas limitações na gestão da água.

A compreensão desta problemática exige a definição dos termos do conflito e tensão, de forma a situá-la no ambiente teórico e metodológico da complexidade ${ }^{1}$, o que permite construir e validar os Indicadores Qualitativos de Tensões no Uso das Águas (IQTA). O conflito é entendido como categoria que se refere ao choque entre os diferentes agentes produtores do espaço urbano-industrial que tornam efetivas suas demandas por água. A tensão, por sua vez, seria uma categoria de análise que acolheria as contradições e, por isto mesmo, revelaria grande potencial de produzir sínteses que conciliariam o conflito e/ou originariam cooperações (Porciúncula \& Alencar, 2019).

\footnotetext{
${ }^{1}$ Capra (2012), Capra \& Luisi (2014), D’Ambrósio (1999), Alencar \& Moreira (2005) e Alencar (2008, 2017), compartilham a perspectiva de uma formulação científica que contemple o fenômeno da vida na construção de suas representações, pautada nas contribuições das ciências contemporâneas e acolha lógicas não científicas constituintes do processo histórico do desenvolvimento humano, como saberes legítimos nestas representações.
} 
Veríssimo (2010, p. 21) apreende que o conflito relacionado ao uso das águas "remete para uma relação de oposição entre indivíduos, grupos ou países, que surge por divergências de sentimentos, opiniões, ideias e/ou ideais, levando à perturbação na tomada de decisões e acções". Neste âmbito, o conflito que se estabelece em torno dos diferentes usos a que as águas se destinam pode resultar em tomadas de decisões e acordos multilaterais para equacionar interesses opostos e assimétricos.

Nesta perspectiva conceitual é imprescindível explicitar que a assimetria dos interesses carrega também assimetria na correlação de forças. Quando esta condição de correlação não é explicitada, o conflito é compreendido de forma limitante, porque é tratado como elemento capaz de equacionar interesses contraditórios de modo maniqueísta. Dito de outro modo, é imprescindível que se reconheça os lados do conflito e que estes se explicitem na medida da sua força e importância política e econômica. Nesta acepção do termo, conflito põe-se o lado mais forte versus o lado mais fraco, os usos mais importantes economicamente em oposição aos menos importantes, sendo uma correlação favorável aos interesses dominantes (Porciúncula, 2017).

Neste estudo, a tensão é uma unidade dos contrários, de acordo com uma lei fundamental da dialética materialista, com possibilidades de produzir nova síntese, diferente do conflito que se encerraria em si. Para tanto, as evidências de tensão do uso da água emergem a partir do entendimento de que a realidade é uma síntese de múltiplas determinações, que são explicativas do fenômeno estudado. As tensões decorreriam do choque entre diferentes interesses e agentes produtores do espaço urbano-industrial, ao tornarem efetivas as suas demandas por águas doces, e outros sujeitos que se apropriam sócio-historicamente ${ }^{2}$ dessas águas para a realização de um modo de vida caracterizado pela relação direta com a natureza, do qual emerge o sentimento de pertencimento ao lugar, ou seja, a identidade territorial.

Os conflitos e tensões pelo uso da água surgem de rupturas do acordo simbólico entre diferentes práticas sociais no espaço e no território. Ascselrad (2004, p. 23) compreende que os conflitos ambientais "deverão ser analisados, ao mesmo tempo, nos espaços de apropriação material e simbólica dos recursos do território". Os conflitos ambientais emergem do problema de que uns se beneficiam mais que outros, enquanto outros grupos sociais sofrem maior custo (Martinez, 2004).

Neste estudo, as tensões, qualificadas como territoriais, refletem a disputa pelo uso das águas doces no espaço metropolitano. O territorial se refere a como o território é usado, resulta da apropriação do substrato material mais a identidade, ou territorialidade, que de acordo com Santos (2007, p. 14) é "o sentimento de pertencer àquilo que nos pertence". Para este autor, no território, lugar da residência, trocas materiais e espirituais, realiza-se o trabalho e a vida.

Nesta constituição, o poder que emerge do território associado à identidade emana da dimensão política contida nas relações sociais, conferindo uma dinâmica própria e repleta de significados ao

\footnotetext{
${ }^{2}$ Um modo de vida que se realiza na relação direta com a natureza, própria do mundo rural, através dos usos das águas doces associados ao lazer; à realização de práticas religiosas, as de matriz africana e as protestantes e católicos; à pesca; à retirada da água diretamente dos mananciais para consumo humano e dessedentação animal foram identificados na Região Metropolitana de Salvador (Porciúncula, 2017).
} 
lugar. Souza (2013) esclarece que, além do poder e da identidade, mostram-se extremamente relevantes na análise do território o reconhecimento das dimensões da cultura, do simbolismo, das teias de significados e da dimensão econômica, especialmente através do trabalho. Haesbaert (2004) compreende que o território acolhe as dimensões política e as relações econômicas e culturais, porque está vinculado ao modo como as pessoas usam a terra, organizam-se no espaço e como elas imprimem significados ao lugar.

Saquet (2007) compreenderá que, para a superação da compreensão simplista de território sem sujeitos sociais ou tais sujeitos sem território, é necessário apreender a complexidade e unidade da vida, de maneira (i)material. Insiste que cada sociedade produz seu território e territorialidades, sendo o território natureza e sociedade, economia, política e cultura, o qual acolhe as interações no âmbito do lugar, objetiva ou subjetivamente, e indica a potencialização dos processos de desenvolvimento.

Para tornar operacional a identificação das tensões e a sua compreensão no contexto da problemática das águas doces no espaço metropolitano da Região Metropolitana de Salvador, foi desenvolvida uma metodologia intitulada de Indicadores Qualitativos de Tensões no Uso da Água (IQTA) ${ }^{3}$. Esta metodologia se filia ao desenvolvimento humano compreendido para além da noção de indicador de qualidade de vida, da perspectiva biológica, da engenharia ambiental, do âmbito da ciência positivista. Acolhe, por sua vez, a inviolabilidade da dignidade humana e da natureza, consideradas nas múltiplas relações existentes entre as dimensões ecológica, econômicas, socioculturais e da espiritualidade.
A metodologia do IQTA acolhe o desafio de inserir a subjetividade como componente importante à interpretação da realidade social, perspectiva que vem se consolidando desde a formulação de indicadores socioeconômicos, a julgar o IDH. Ainda que acolher as subjetividades na interpretação da realidade social seja um avanço teórico-prático, o que no caso estudado se reporta à dimensão da vida metropolitana não percebida e valorizada pelo planejamento governamental, com potencial prejuízo à conquista do desenvolvimento local, não obstante, reclama por um "[...] equivalente avanço metodológico" que seja capaz de mensurar tais subjetividades (Alencar, 2006, p. 161). Neste estudo admitem-se, além dos valores do mercado, os ecológicos, a biodiversidade, os valores simbólico-cognitivos e culturais dos territórios.

A inserção da subjetividade na análise da dinâmica metropolitana pelo IQTA sobre uso e degradação das águas doces é orientada por rigor teórico e metodológico, assim como orientou a elaboração de índices e indicadores qualitativos amplamente utilizados, a exemplo do IDH, do Índice Relativo e Qualidade de Vida (IRQV), do Índice de Qualidade de Vida Urbana (IQVU), do Índice Paulista de Responsabilidade Social (IPRS) e dos Indicadores Qualitativos de Ruralidade Metropolitana (IQRM).

É válido ressaltar que, no ambiente discursivo e reflexivo no qual se compreende as tensões no uso das águas no espaço metropolitano, subjaz crítica ao esgotamento do modelo civilizatório urbano-industrial. Trata-se de discurso que se distancia das análises estritamente quantitativas e disjuntivas, que são as dominantes. A metodologia do IQTA apreende como evidências empíricas eventos

${ }^{3}$ Convido ao leitor a conhecer metodologia mais detalhada em Porciúncula (2017). 
que revelam a disponibilidade hídrica natural; a degradação sistemática dos mananciais no espaço metropolitano; os impactos da urbanização/industrialização, sobretudo, na forma com que o ideal de modernidade é alcançado ao se apropriar das águas doces no espaço da cidade ${ }^{4}$. Esse ideal de modernidade, anacrônico, aprofunda a falha metabólica da relação sociedade-natureza constatada pelo afastamento dos processos ecológico-naturais responsáveis pela manutenção do frágil equilíbrio ecossistêmico. $\mathrm{O}$ interesse da ecologia abrange a dinâmica de ecossistemas e da paisagem, temas das geociências e ciências do homem (Barbault, 2011), o que permite confrontá-la com as questões socioambientais, como as tensões do uso das águas doces.

$\mathrm{Na}$ abordagem metodológica proposta, é reconhecida a presença de "sinais" de um novo padrão civilizatório, que se revela de forma contra-hegemônica no espaço metropolitano, de onde emerge uma relação com a natureza marcada por significados, historicidade e identidades territoriais que é reivindicada pelos sujeitos sociais como indicativo do desejo de permanecer em relação direta com a natureza por meios das águas doces, vindo a caracterizar um movimento de reapropriação social da natureza (Toledo, 2013). Esse movimento contra-hegemônico se mostra como potencial de desenvolvimento humano alcançado na (re)forma com que os sujeitos rurais e urbanos se relacionam culturalmente com as águas. Alencar (2019) assinalará que a natureza, a ruralidade, territorialidade e crítica atual ao padrão de desenvolvimento urba- no-industrial constituem referências à análise da vida humana no espaço metropolitano.

No espaço metropolitano, o IQTA se configura como metodologia qualitativa elaborada com o mesmo intento do IQRM, o qual, de acordo com Alencar (2008), destacaria as condições de coexistência entre ruralidade e urbanidade no espaço metropolitano, e esforços catalisados para a superação do padrão civilizatório atual. Desta forma, a sua aplicação almejou compreender a distribuição das evidências empíricas que tensionam os modos de vida rural e urbano na relação com o uso das águas e identidades territoriais no espaço da Região Metropolitana de Salvador (RMS), Bahia, Brasil. Estas relações teriam sido invisibilizadas e/ou subalternizadas no discurso daqueles que planejaram, produziram e organizam tais espaços, decorrendo daí a condição de lugar de tensões pelo uso das águas.

\section{Rural, ruralidade e identidade territorial no espaço metropolitano}

Santos (2012) propõe, de uma forma direta, que o modelo cívico se constitui, entre outros, de dois componentes fundamentais, que seriam a cultura e o território. Este autor reclama mudanças no uso e gestão do território para que se possa criar uma cidadania que ofereça respeito à cultura e tenha como busca a liberdade. Alencar (2008), quem desenvolveu os Indicadores Qualitativos de Ruralidade Metropolitana (IQRM), destacou que o

\footnotetext{
${ }^{4} \mathrm{O}$ ideal de modernidade ao qual nos referimos deve ser apreendido considerando a noção de modernidade que tradicionalmente fora incorporada no Brasil, como bem assinalou Siqueira (2010, p. 225). De acordo com a autora, "a ansiedade pelo moderno e a expansão da indústria passaram a ser vistas sob o signo da modernização" no Brasil, sobretudo a partir da década de 1970, com o processo de metropolização, que impositivamente produziu o espaço urbano assentado num modelo de desenvolvimento que persiste na atualidade, aprofundando as desigualdades sociais e degradando a natureza.
} 
propósito, ao inserir as subjetividades, seria tecer uma crítica que questiona o modo de vida relativo ao padrão civilizatório atual,

[...] que o avanço tecnológico, associado à organização capitalista da sociedade, imprimiu como padrão metropolitano de desenvolvimento, distanciando o ser humano de sua condição de ser natural e opondo a experiência urbana à experiência rural. Em segunda instância está o aprendizado que esse modo de vida possibilitou às pessoas que têm vivência de ruralidade no ambiente metropolitano e cuja dinâmica lhe é antagônica (Alencar, 2008, p. 118).

Esse posicionamento suscita uma noção de desenvolvimento inteiramente complexa e integra críticas às concepções reducionistas de desenvolvimento que "focalizam no crescimento econômico o cerne do processo de desenvolvimento; no desenvolvimento industrial" (Alencar, 2008. p. 109). E, com isto, negligenciam outros potenciais de desenvolvimento a serem alcançados quando a dimensão humana é plenamente requisitada. O desenvolvimento econômico de base territorial apropriar-se-ia de tal base, com dinâmica própria e identitária, sendo capaz de dinamizar com equilíbrio o caráter socioambiental do desenvolvimento.

A perspectiva teórica de ruralidade metropolitana foi desenvolvida nos marcos do pensamento complexo de forma a possibilitar o reconhecimento da [...] condição de rural e de urbano configurando um padrão de desenvolvimento em coexistência tensionada pela diversidade de modos de vida em relação com a natureza e sob a égide do capitalismo contemporâneo (Alencar, 2008, p. 114).

Assim, a dinâmica metropolitana na RMS radicaliza a intensidade da condição urbana de aglomeração como evidência empírica e inspira a proposição da noção de ruralidade metropolitana, entendida como recurso interpretativo à medida que dá subsídios à requalificação do rural a partir de demandas da metrópole e de questões ambientais. Neste processo, com hegemonia do padrão civilizatório urbano-industrial, a condição rural seria invisibilizada como espaço social de realização para o poder instituído e para a ciência que erige modelos analíticos tendenciais e orientam o planejamento. Nesse contexto, instituições, ciência e planejamento, apontaram como relevante o desenvolvimento capitalista da RMS, atingindo o território em suas identidades territoriais ao territorializar o capital (Alencar, 2019).

Nos marcos dessa territorialidade construída sob a égide da modernidade, ainda que se reconheça a condição rural " [...] a intensidade dos eventos constitutiva do ambiente teoricamente afastaria o rural por não acompanhar a modernidade”, será ela a responsável por fazer "[...] emergir o rural como relação com a natureza, como modo de vida e potencial econômico, através de uma visão crítica sobre a qualidade de vida metropolitana." (Alencar, 2006, p. 153). A compreensão dialética das relações entre o rural, no urbano, metropolitano, poderia ser percebida em função de um tipo de política e de cultura da modernidade. Estas noções de rural e urbano, apreendidas relacionalmente no espaço metropolitano, como modo de vida, sob a hegemonia do urbano, integram uma realidade social rica em determinações e exemplos do desenvolvimento humano almejado, com inúmeras conquistas obtidas pela espécie humana a partir da tríade ser humano, conhecimento e natureza. Esta perspectiva dialoga com a Ecologia Humana, que se preocupa, de acordo com Alvin (2014), com estudos de natureza ecocêntrica, que visam integrar o ser humano ao planeta. 
A apreensão das determinações que compõem a realidade metropolitana na sua relação com as águas doces se deu pelo exercício analítico de síntese. Neste processo, perscruta-se a realidade social, objeto de interesse, por meio da obtenção de evidências, que podem revelar o conteúdo das tensões no uso das águas. Reportadas ao ambiente teórico-reflexivo no qual as explicações representativas das evidências de tensões foram elencadas, as tensões são qualificadas e explicadas a partir de um conjunto teórico de determinações. Este esforço reflexivo e interpretativo das evidências torna possível apreender a complexidade, a qual se materializa no espaço metropolitano e acolhe as diferentes interrelações entre os modos de vida rural e urbano com as águas doces.

Alencar (2006; 2008), Porciúncula (2017; 2019) e Alencar (2017) apontam que a biogeodiversidade e ecologia de paisagens da Mata Atlântica e ecossistemas costeiros e marinhos - rios, lagoas, aquíferos e o mar - em seus usos múltiplos, ampliam os modos de vida e a riqueza de identidades territoriais na RMS, onde ruralidades se movem pelo progresso urbano e pela nostalgia do rural tradicional. A noção de ruralidade como recurso de análise da realidade social na Região Metropolitana de Salvador carrega a (re)emergência do rural, ao invés do seu desaparecimento, e da questão agrária, como características do mundo rural.

\section{Aplicação do IQTA em espaço regional metropolitano}

Indicadores Qualitativos de Tensão no Uso das Águas (IQTA) possibilitaram caracterizar tensões territoriais pelo uso das águas doces observadas entre
2005 a 2015, na Região Metropolitana de Salvador (RMS), constituída pelos municípios de Salvador, Camaçari, Lauro de Freitas, Simões Filho, Candeias, Dias d'Ávila, São Sebastião do Passé, Mata de São João, Vera Cruz, São Francisco do Conde, Pojuca, Itaparica e de Madre de Deus. O IQTA demonstra a coexistência entre ruralidade e urbanidade no espaço complexo, metropolitano, onde o processo de urbanização induzida pela industrialização gerou territórios tensionados como lugar de conflitos.

O levantamento de evidências de disputa pelo uso das águas doces atendeu metodologicamente a dois critérios: i) observância da área de trabalho com buscas por notícias exclusivas da RMS e/ou dos treze municípios que a constitui; e ii) identificação de notícias que contivessem descritores-chave específicos: água, falta d'água, desabastecimento, infraestrutura, risco, abandono, abastecimento, lagoa, rio, córrego, canal, recurso hídrico, poluição da água, barragem, fonte, poço, cisterna, dique, manancial, saneamento ambiental, meio ambiente, parques, área de preservação permanente (APP) e área de preservação ambiental (APA).

A principal fonte para a identificação das evidências foram jornais impressos e digitais, usada amplamente na pesquisa historiográfica. Seguindo Lapuente (2015, p. 1), verificou-se que "os jornais devem ser utilizados criticamente" pelo pesquisador, "para não correr o risco de se deixar levar pelo discurso da fonte e, consequentemente, realizar uma análise precipitada, acrítica e superficial'. Para tanto, procedeu-se uma fundamentação teórica e metodológica que considerou que as evidências seriam notícias referentes a situações, ou eventos, que envolvem problemas diversos no qual a água seria central em questão, desde que houvesse repercussão por comoção social ou visibilidade da questão, em 
especial se próximo a datas comemorativas do Meio Ambiente e dia Internacional da Água.

A principal fonte de evidências foi o jornal A Tarde, com circulação regular desde sua fundação em 1912, de onde foram apreendidas ocorrências de eventos extremos com repercussão da opinião pública. As evidências empíricas, posteriormente categorizadas como tensões pelo uso das águas, foram também obtidas em jornais de circulação local e regional, considerados fontes auxiliares de pesquisa: Correio*, Tribuna da Bahia, É Massa!, Dias d'Ávila Acontece, Candeias Mix, Madre Notícias, Fala Simões Filho, Folha do Recôncavo e outros.

Para ampliação da base de dados referentes aos municípios que eram raramente citados, a exemplo de São Francisco do Conde, Candeias, Simões Filho, Pojuca, São Sebastião do Passé, nos jornais publicados na metrópole, procedeu-se com buscas online em periódicos locais. Os endereços eletrônicos foram obtidos no Guia de Mídia: jornais, rádios, revistas, etc. nas escalas regional, municipal e local. $\mathrm{O}$ tipo de fonte de dados gerou a constatação de que apenas nos periódicos locais esteve visível a questão de tensões pelo uso das águas naquela escala e relevância para os sujeitos do lugar. Este tipo alternativo de fonte local auxiliou na aquisição de dados e no esgotamento das possibilidades de encontrar evidências na escala do município que, por algum motivo, foram ignoradas pelos jornais de grande circulação da metrópole Salvador. Como fonte secundária de pesquisa, utilizamos dissertações, teses e artigos, atendendo aos mesmos critérios de mineração de dados utilizados nas demais fontes.

As ocorrências, após serem identificadas, foram fotografadas e agrupadas em um banco de dados, organizado por ano/mês, e, em seguida, foram qualificadas como sendo ou não uma evidência. As evidências reconhecidas como tensões pelo uso das águas foram inseridas no "Quadro geral das Tensões no uso das águas em Salvador e RMS', que reúne evidências, tensões e determinações 5 .

Em síntese, as evidências são categorias metodológicas interpretativas e analíticas de eventos empíricos de modo a lhes atribuir conteúdo de fenômeno e, a partir daí, tipificá-los conforme a metodologia explicada. Depois de reconhecidas as evidências, procedemos a sua classificação de acordo com as seguintes tensões: tensões pela apropriação da água (T-1): apropriação da água por disputas entre o econômico e o não econômico, disputa entre os diferentes usos econômicos, disputa entre o rural e o urbano e disputa entre o urbano e a água; usos geradores de riscos ambientais (T-2): produção de riscos e produção de eventos ambientais; e usos da água em atividades culturais: uso cultural como recursos naturais e uso cultural como água, cognitivo-simbólico (T-3).

As evidências qualificadas pelo conteúdo das tensões elucidaram a explicação do fenômeno, de disputa pelo uso das águas, a partir de seis determinações teórico-metodologicamente formuladas (abstrações) (Tabela 1) e que possibilitaram identificar e agrupar as variáveis independentes e dependentes (empírico) relacionadas às dimensões econômicas, culturais, políticas, naturais, subjetivas e de sociabilidade ali predominantes e apreendidas na escala regional do fenômeno. Nesta pesquisa, emergiu a Determinação do Planejamento (DP), sendo as outras determinações herdadas e adaptadas do IQRM, segundo Alencar (2008).

${ }^{5}$ Convidamos os leitores a consultar o referido quadro em: http://labgeo.ucsal.br/aguas/iqta/ 
TABELA 1 - Classificação das determinações das disputas pelo uso da água na RMS.

\begin{tabular}{ll}
\hline Determinações & Descrição \\
\hline Determinação Geoambiental (DG) & Tensiona ao opor leis, demarcações, denúncias de riscos ou eventos ao uso da água. \\
\hline Determinação Rural (DR) & $\begin{array}{l}\text { Tensiona ao permanecerem os usos mais diretos da água, quer produtivo, social, simbólico ou } \\
\text { cultural. }\end{array}$ \\
\hline Determinação Urbana (DU) & $\begin{array}{l}\text { Decorre quando usos são estabelecidos de forma mediada por processos ou instrumentos } \\
\text { tecnológicos e tornando menos evidente a existência dos mananciais. }\end{array}$ \\
\hline $\begin{array}{l}\text { Determinação do Modo de } \\
\text { Ocupação (DMO) }\end{array}$ & $\begin{array}{l}\text { Denota ritmo e modo de apropriação da natureza, com risco ou comprometimento dos mananciais, } \\
\text { condicionada pela hegemonia da acumulação capitalista. }\end{array}$ \\
\hline $\begin{array}{l}\text { Determinação do Conhecimento } \\
\text { Científico (DCC) }\end{array}$ & $\begin{array}{l}\text { Expressa usos da água justificados ou contestados pela autoridade das descobertas ou explicações } \\
\text { científicas expressas em tecnologias de processo, de organização ou de equipamentos. }\end{array}$ \\
\hline Determinação do Planejamento (DP) & $\begin{array}{l}\text { Expressa a orientação do modelo de desenvolvimento metropolitano para a apropriação da } \\
\text { natureza e uso das águas regulado e/ou justificado pela ação institucional e administrativa. }\end{array}$ \\
\hline
\end{tabular}

FONTE: Elaborado pelos autores.

Na elaboração do IQTA foi explicitada a escolha de apreender apenas as águas doces como elemento da natureza em disputa entre os modos de vida rural-urbano, em espaço metropolitano. Desta maneira, as dimensões subjetivas, base metodológica dos indicadores qualitativos, emergem como um potencial de apreensão de evidências examinadas como "[...] conteúdo das condições de vida", observadas "[...] em escala regional, em território metropolitano, a partir de relação entre os modos de vida rural e urbano, questões sociais que justificam ações públicas com vias à 'sustentabilidade do planeta"" (Alencar, 2008, p. 110).

O IQTA foi formulado com o propósito de operacionalizar uma realidade complexa, a partir da noção de ruralidade metropolitana, e com potencial de, ao ser aplicada, revelar as dimensões da realidade social invisibilizadas em espaço metropolitano. Esta metodologia compreende a realidade social a ser apreendida como uma síntese de múltiplas determinações, sendo possível a proposição de novas sínteses, uma vez que a realidade estaria em constante movimento dialético em que ruralidade e urbanidade integram um espaço complexo e diverso, o metropolitano.

\section{Resultados e discussão}

\subsection{Classificação das evidências em categorias de tensões}

A Figura 1 mostra, de acordo com a aplicação do IQTA, que foram identificadas 1.006 evidências de tensões ${ }^{6}$ no uso das águas em espaço regional metropolitano, entre 2005 e 2015 . Observa-se que 2006 e 2015 foram os anos com maior registro de evidências (206 e 266), e 2012, com menos evidências (33).

Os múltiplos eventos neste período (20052015) decorreriam da forma como o espaço metropolitano na RMS fora produzido apoiado pelo modelo civilizatório de desenvolvimento urbano-industrial, que, hegemônicos, tensionaram os modos

\footnotetext{
${ }^{6}$ Vide http://labgeo.ucsal.br/aguas/iqta/
} 
de vida e as relações socioespaciais ao instituir impositivamente um modelo público/privado de abastecimento de água ${ }^{7}$. A adesão compulsória ao modelo resultou na substituição das fontes de água utilizadas para o abastecimento (rios, nascentes, lagoas, fontes naturais e artificiais), influenciando na forma como os sujeitos rurais e urbanos passaram a se apropriar das águas doces. Entretanto, a adesão ao modelo não garantiu o pleno abastecimento de água, podendo ser verificado em todos os municípios inseridos na RMS que a suspensão do abastecimento público por longos períodos é uma realidade conhecida, sobretudo nos bairros periféricos da metrópole Salvador, onde a suspensão do abastecimento ultrapassa as 24 horas.

Foram verificados, igualmente, ainda em relação à tensão $\mathrm{T}-1$, as pressões da urbanização que conduzem a grandes períodos de suspensão do abastecimento humano de água superiores a 24 horas nos municípios mais próximos à metrópole, especialmente no município de Dias d'Ávila. No município Lauro de Freitas foi possível identificar a intensa urbanização com pressões cada vez maiores sobre o rural, apreendido na dinâmica social enquanto modo de vida, com a degradação de importantes rios, a exemplo do rio Joanes, comprometendo a pesca, a mariscagem, o banho e o lazer, e a captação direta de água do rio para o consumo. Tem-se a permanência dos usos diretos da água (nascentes, rios, lagoas), ainda que ofereça risco à saúde e, dado as evidências de poluição, como resposta imediata à suspensão do abastecimento público de água durante longos períodos, ou à pesca e rituais religiosos, ou como forma de resistência ao modo de vida urbano-industrial.
A abundância de águas no município de Dias d'Ávila, cujas águas eram tidas como medicinais, rendeu-lhe o título de Estância Hidromineral, na década de 1960, e a alcunha dos munícipes e visitantes de "Cidade das Águas". De acordo com Porciúncula (2011), o quadro de degradação das águas resultado da poluição por lançamento de esgotos in natura de origem doméstica e industrial, aliado à intensa exploração das águas superficiais e subterrâneas para usos urbano-industriais, provou a deterioração da qualidade das águas e fez com que, vinte anos após o início do processo de metropolização, Dias d'Ávila perdesse o título de Estância Hidromineral e convivesse com períodos de falta de abastecimento público de água que já excederam nove dias.

Contudo, nos dois exemplos dados acima, é verificada a permanência dos usos diretos da água (nascentes, rios, lagoas), ainda que oferecendo algum tipo de risco à saúde, dadas as evidências de poluição, seja como resposta imediata à suspensão do abastecimento público de água durantes longos períodos seja para pesca e rituais religiosos ou como forma de resistência ao modo de vida urbano-industrial.

Registrou-se no conteúdo das evidências entre os anos de 2005-2015, desde a suspensão no fornecimento de água em intervalos superiores a 48 horas, o que já caracteriza um evento ambiental, às altas perdas no sistema de distribuição de água; à degradação crescente de rios por despejo de efluentes domésticos e industriais; à ocupação irregular em áreas de proteção permanente (APP) de rios e lagoas; ao uso recreativo dos lagos dos reservatórios apesar da falta de segurança e qualidade ruim das águas; ao comprometimento de atividades culturalmente

\footnotetext{
${ }^{7}$ A Empresa Baiana de Águas e Saneamento (EMBASA), criada em 1971, é uma sociedade de economia mista de capital autorizado, pessoa jurídica de direito privado, tendo como acionista majoritário o Governo do Estado da Bahia. (http://www.embasa.ba.gov.br/index.php/institucional/a-embasa/apresentacao
} 


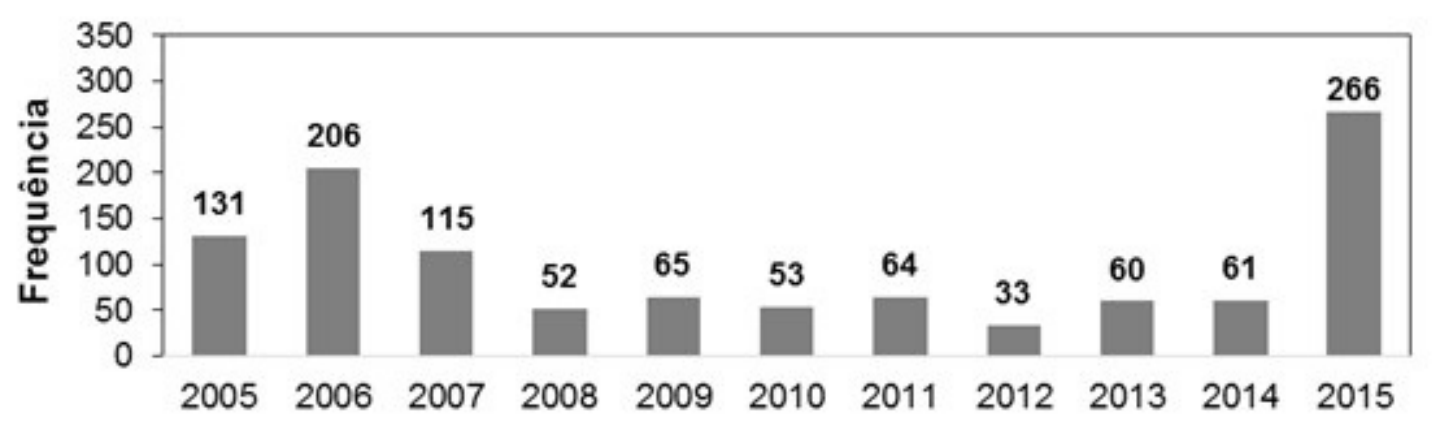

Evidências

FIGURA 1 - Distribuição das evidências de tensões no uso da água na RMS (2005-2015).

FONTE: Elaborado pelos autores.

estabelecidas, como a pesca, devido à degradação das águas dos rios e de outros usos da natureza.

A caracterização das evidências indicou que estas emergiram na escala do município e, muitas vezes, na escala do bairro, o que permitiu espacializá-las nos mapas de distribuição das tensões no uso das águas doces na RMS, como revelaram as Figuras 2, 3 e 4. Houve a predominância da tensão pela apropriação da água (T-1), a qual incidiu, majoritariamente, nas áreas onde a exploração e a demanda por água para usos urbanos e industriais são intensivas. Observou-se pressão pelo consumo intensivo da água, do Aquífero São Sebastião e da Barragem de Santa Helena nos municípios de Camaçari e Dias d'Ávila, para atender a demanda por água de boa a excelente qualidade do Polo Petroquímico.

A expressividade da tensão pela apropriação da água no espaço RMS, complexa e diversa, deslindou, igualmente, que a ruralidade e urbanidade se encontram no mesmo espaço, o metropolitano, aqui configurado na disputa territorial pelo uso da água. Este contexto torna possível, de acordo com Porciuncula \& Alencar (2010), a existência da ruralidade onde a urbanização induzida pela industrialização produziu territórios tensionados como lugar de conflito, tendo em vista que se constituir como território supõe a apropriação de espaços por diferentes sujeitos e agentes econômicos que neles produzem e reproduzem diferentes interesses.

A Figura 3 apresenta a distribuição da tensão geradora de riscos e eventos ambientais (T-2), que aparece com menor incidência quando comparada às tensões pela apropriação das águas (T-1). Entretanto, a presença da tensão geradora T-2 representa um indicativo de falha no sistema de gestão das águas doces, a perda da qualidade das águas doces, riscos à saúde humana e ao equilíbrio ambiental. Dessa forma, configura-se um cenário de longos períodos de suspensão do abastecimento de água e a poluição dos mananciais por efluentes líquidos domésticos e industriais, muitos destes há pouco compunham o sistema de abastecimento público de água da metrópole. 


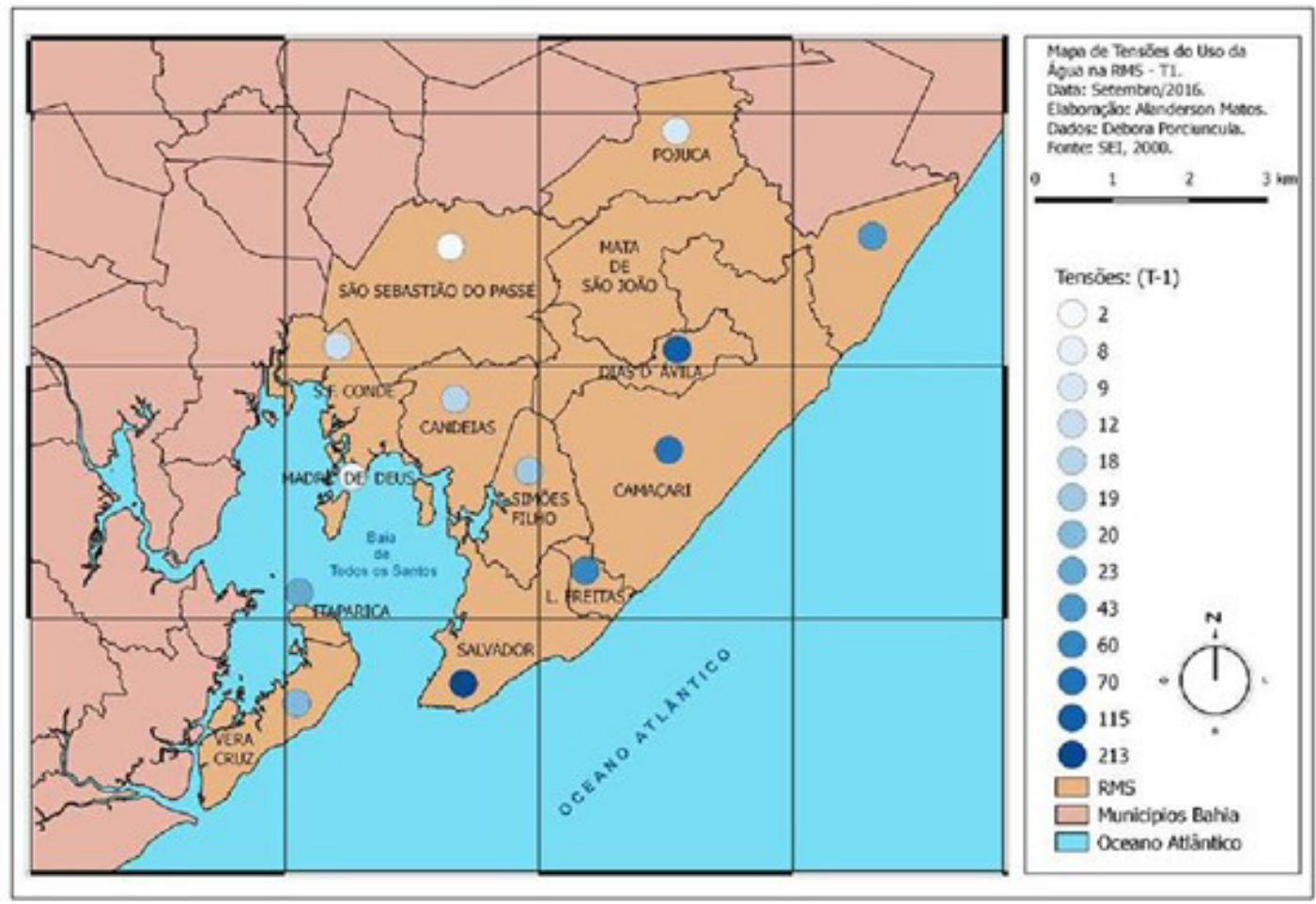

FIGURA 2 - Mapa de tensões pela apropriação das águas na RMS (T-1) (2005-2015).

FONTE: Elaborado pelos autores (Porciúncula, 2017, p. 220).

A tensão geradora T-2 coloca em suspeição a eficiência do modelo de saneamento ambiental metropolitano em vigor, e a sustentabilidade, uma vez que à medida que se apropria, usa e degrada os corpos hídricos mais próximos, avança na busca de mananciais cada vez mais distantes da $\mathrm{RMS}^{8}$, sem se responsabilizar pela sua proteção, acentuando o quadro de falhas no saneamento ambiental. A poluição decorre, principalmente, do despejo de altas cargas de poluentes nos mananciais, o que promove o extravasamento da rede de esgotos em áreas de alta vulnerabilidade ambiental, comprometendo a qualidade da água de rios e reservatórios. Este modelo insustentável e injusto preteriu todas as fontes alternativas para o abastecimento, não as tornando sequer complementares ao abastecimento público, ao invés, punha em descrédito sua potabilidade e desincentiva o seu uso?.

\footnotetext{
${ }^{8}$ De acordo com Porciúncula (2017), 60\% da água consumida na RMS provém de mananciais que estão fora dela, enquanto os rios inseridos na RMS estão completa ou parcialmente degradados. Este fenômeno decorre da expansão metropolitana para além dos limites físicos da própria região, alcançando outros territórios e impactando diretamente os mananciais e os sujeitos que neles vivem.

${ }^{9} \mathrm{O}$ uso de fontes públicas é uma realidade presente, por exemplo, em Paris, na França, com boa prática de gestão comunitária da água, difícil de ser ignorado no contexto atual da RMS, em que as crises do abastecimento tornaram-se realidade frequente, sobretudo nas periferias da metrópole.
} 
A categoria T-2 refletiu a questão das águas na ruralidade metropolitana, expondo os riscos e eventos ambientais que alertam quanto ao desgaste do modelo civilizatório urbano-industrial que segue degradando mananciais e gerando vários riscos: $\mathrm{o}$ risco de faltar água por mais de 48 horas; de ter acesso à água com qualidade ruim; de contrair doenças de veiculação hídrica; de afogamentos, de enchentes, etc. Observa-se a intensidade com que a tensão T-2 incidiu nos municípios de Salvador, Lauro de Freitas, Camaçari, Dias d'Ávila e Mata de São João, conforme apresentado na Figura 3.

A categoria de tensões no uso da água em atividades culturais (T-3) foi verificada amplamente na metrópole Salvador e demais municípios, onde constatamos a degradação e as pressões crescentes sobre os mananciais. Os processos de metropolização, tanto o tradicional, a partir da década de 1970, quanto do turismo, a partir da década de 1990, no litoral dos municípios de Camaçari, Lauro de Freitas e Mata de São João, tensionaram o modo de vida rural. Entretanto, a T-3 nos permite reconhecer a resistência deste modo de vida que segue em conflito, reclamando por seu espaço e pelo direito dos sujeitos sociais de seguir inter-relacionando-se cultural e simbolicamente com as águas, como potencial de desenvolvimento humano.

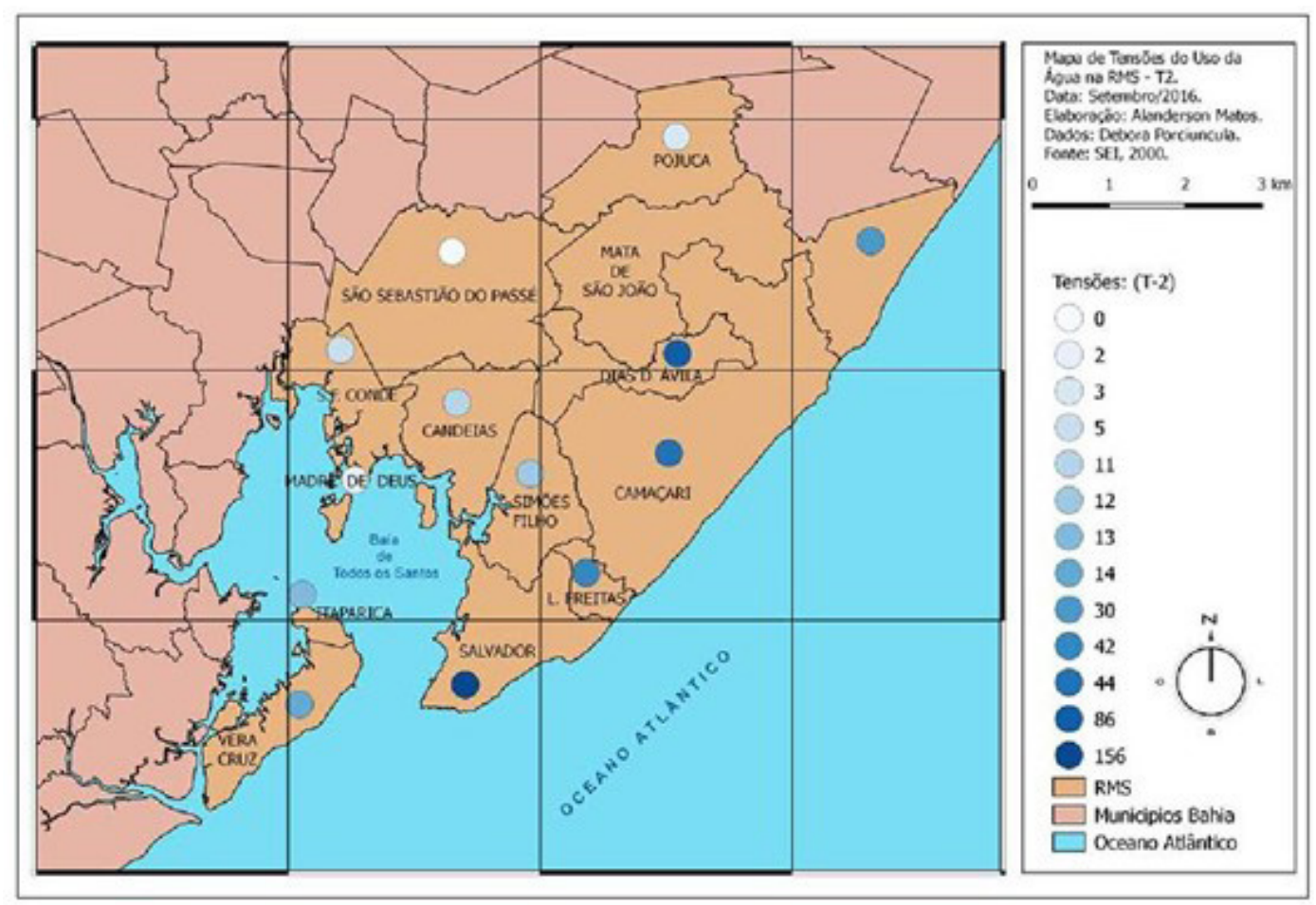

FIGURA 3 - Mapa de tensões geradoras de riscos e eventos ambientais (T-2) (2005-2015).

FONTE: Elaborado pelos autores (Porciúncula, 2017, p. 222). 


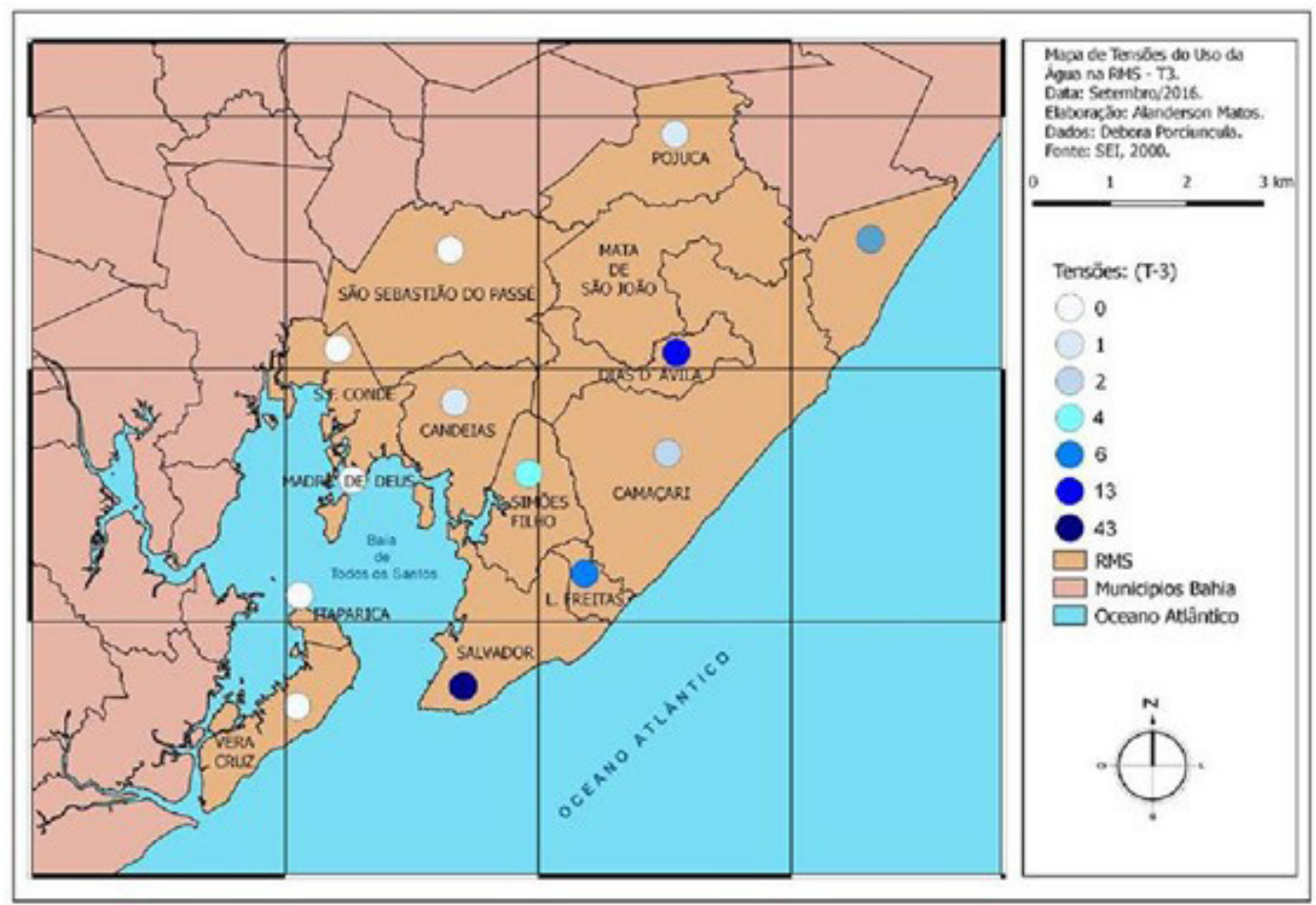

FIGURA 4 - Mapa de tensões no uso da água em atividades culturais (T-3) (2005-2015).

FONTE: Elaborado pelos autores (Porciúncula, 2017, p. 224).

As tensões no uso da água em atividades culturais (T-3) apresentaram uma menor frequência relativa e, por isso mesmo, confirmam o êxito do modo de vida urbano-industrial como modo hegemônico. No entanto, essa tensão é representativa da permanência da ruralidade em espaço metropolitano ao revelar uma presença contra-hegemônica que se apropria das águas culturalmente, como natureza, seja por via da religiosidade, do lazer, da pesca, da contemplação, ou pelos demais usos não econômicos. A resiliência de modos de vida rural, a partir da noção de ruralidade metropolitana, revela-se contra-hegemônico, como propôs Alencar (2008), porque a natureza, quando apropriada e transfor- mada em mercadoria, passa a ser recurso natural evidente para o modo de vida rural, mas permanece invisível sob a hegemonia metropolitana.

Em síntese, destacamos que as figuras 2, 3 e 4 ilustram, em certa medida, a contradição do modelo de desenvolvimento urbano-industrial, que inviabiliza os usos culturais da natureza (T3) frente às tensões por apropriações da natureza (T1) por riscos e eventos ambientais (T2) decorrentes dessa apropriação. A intensidade das tensões 1 e 2 na RMS, concentrando-se nos municípios de Salvador, Lauro de Freitas, Camaçari e Dias D’Ávila, refletem como se dá a produção socioespacial destes municípios, concentrada e conduzida pela metro- 
polização capitaneada pela industrialização quer de transformação quer do turismo, configurando a hegemonia do modelo urbano-industrial. A invisibilização dos usos culturais da natureza enquanto prática cotidiana pautada na imprensa é outra expressão dessa metropolização. Assim, a tensão 3 representa uma expressão contra-hegemônica em relação aos usos da natureza, e as tensões 1 e 2 são relevantes para apresentar supremacia do modelo urbano-industrial produtor de falhas metabólicas. O município de Camaçari, o mais agrícola e também o mais industrializado da região, coerentemente, expressa a contradição desse desenvolvimento.

\subsection{Compreensão das tensões no uso das águas}

As tensões no uso da água obtidas a partir do levantamento das evidências, de acordo com a abordagem metodológica do IQTA, foram exemplificadas, sendo identificadas as determinações explicativas de tensões, classificadas na Tabela 1. Representadas pelas Determinações Rural (DR), Urbana (DU), Geoambientais (DG), do Modo de Ocupação (DMO), do Conhecimento Científico (DCC) e do Planejamento (DP). Segue-se a análise das determinações e tensões pelo uso das águas na RMS:

a) Tensões pela apropriação das águas (T-1)

Foi escolhida uma situação relativa à instalação do serviço de fornecimento de água potável pela Empresa Baiana de Água e Saneamento S.A. (Embasa), em Arembepe, nas imediações do Rio Capivara, no município de Camaçari, RMS. Esta instalação foi acompanhada da exigência de desativação dos poços perfurados no lençol freático, porque o serviço de abastecimento de água potável estaria garantido. Outra situação se reporta à reclamação quanto ao fornecimento de água potável, realizada por um morador do bairro de Matatu de Brotas, no município de Salvador.

Água para beber não foi o problema mais grave apontado pelos moradores de outras localidades, e sim a extinção do hábito de buscar água nas fontes e cisternas de Ilha dos Frades ou em Madre de Deus em períodos de estiagens. No entanto, em outra localidade, “[...] De acordo com dados oficiais veiculados no site oficial da Seinfra, o sistema de abastecimento de Bom Jesus é composto por 3,6 $\mathrm{km}$ de tubulação subaquática em terra firme, que trazem através das adutoras a água de Pedra do Cavalo após tratamento em Candeias". (Mata, 2008, p. 8). DU; DP

Sou um cidadão brasileiro, baiano e soteropolitano. Na nossa residência, usamos água como em qualquer outro lugar do mundo. Lavamos roupas, tomamos banho, etc. Resido na zona urbana, no bairro de Matatu de Brotas, em um prédio na frente da rua principal, área considerada o coração do bairro. Não temos cisternas, e nem chafariz onde poderíamos nos abastecer. Portanto, estou indignado com a empresa responsável pelo abastecimento de água, por nos deixar vários dias na seca, achando que estamos na zona rural, onde pelo menos existem rios ou lagos para abastecimento da população. (Azevedo, 2005, p. 2). DU; DP

No primeiro caso, a EMBASA se apropria das águas de Arembepe, impõe o uso econômico, urbano, torna-a um recurso natural, e propõe aos moradores das Ilhas e de Arembepe, cujo modo de vida é rural, que abandonem a relação cultural com 
as águas doces. O planejamento governamental se mostra alheio à identidade territorial e à cidadania, a qual se constitui, entre outros, da cultura e do território.

A interrupção do abastecimento de água atinge os moradores da metrópole, em um bairro plenamente urbanizado, onde a relação com as águas é mediada pelo monopólio pela EMBASA. Atribui-se, por aquele que se diz cidadão urbano, os problemas do fornecimento de água potável e o uso direto da água, de rios, lagos, cisternas e chafarizes, ao que ele acredita ser próprio ao modo de vida rural. Este olhar a partir do urbano não apreende que o modelo cívico da modernidade urbana-industrial também atinge o espaço rural, e que se apropria da natureza e a degrada.

Nestes exemplos, a Determinação Urbana (DU) explica parcialmente as tensões pela apropriação das águas, quanto à disponibilização da infraestrutura para o abastecimento urbano de água, considerada inerente à condição do modo de vida urbano. Para tanto, foi exigida a extinção da prática de captação de água direta em fontes naturais, como os poços perfurados no lençol freático, usos culturais da água, explicada pela Determinação Rural (DR). Observam-se, igualmente, as tensões pelo uso da natureza em atividades culturais (T3), cuja síntese das determinações DU, DR e a Determinação do Planejamento (DP) concretizam abstratamente a realidade (o concreto pensado).

A Determinação do Planejamento (DP) emerge do projeto de modernidade metropolitana, sendo suficiente a promessa ao acesso à água encanada e potável, regularmente, sem o reconhecimento ou questionamento da origem dessa água, dos caminhos percorridos até o destino, perdas, ou as condições socioambientais dos municípios que a fornecem, a exemplo da carência de abastecimento regular, como no caso de Dias d'Ávila - Ba.

b) Usos geradores de riscos ambientais (T-2)

Um caso representativo das tensões dos usos geradores de riscos ambientais retrata os ricos e impactos ambientais decorrentes da retirada de areia em áreas protegidas pela Lei $n^{\circ} .9 .985 / 2000$ (Brasil, 2000), que constitui o Sistema Nacional de Unidades de Conservação (SNUC), no município de Lauro de Freitas.

Extração ilegal de areia ameaça o equilíbrio do Rio Joanes-Ipitanga - [...] a extração ilegal de areia na Grande Salvador pode comprometer o equilíbrio do rio Joanes-Ipitanga, em Lauro de Freitas, principal abastecedor de água da capital e que fica dentro da área de preservação ambiental (APA) de mesmo nome do curso hídrico. Gestor da APA, o engenheiro agrônomo Geneci Souza, do Instituto de Meio Ambiente e Recursos Hídricos (Inema), diz que a subtração de areia em locais de restinga causa interferência na biodiversidade, perda da proteção contra o salitre e desequilíbrio no balanço hídrico. Vale lembrar que o rio Joanes-Ipitanga responde por $40 \%$ do abastecimento da capital. [...] "Um dos problemas mais sérios na APA é a retirada de areia, com a consequente supressão da vegetação. E isso acarreta o assoreamento das águas superficiais, lençóis freáticos e mananciais", enumera Souza. [...] (Franco, 2014, p. 3). DG; DMO; DU.

Neste caso, a Determinação Geoambiental (DG) explica o comprometimento de mananciais e a perda da biodiversidade, com impacto ambiental nos rios que do sistema de abastecimento de água Joanes-Ipitanga, responsável por $40 \%$ do abastecimento da RMS, com a possibilidade de 
assoreamento dos cursos d'águas e nascentes, além de explicitar a oposição à demarcação da Área de Proteção Ambiental. Articulam-se à DG, as Determinações do Modo de Ocupação (DMO) e Urbana (DU), que explicam respectivamente, por partes, a destruição do ecossistema, com a extração de areia para a construção civil; alterações de ritmo e a forma de uso da natureza. A síntese dessas determinações aproxima-se da realidade objetiva como realidade concreta, explicada.

\section{c) Uso da natureza em atividades culturais (T3)}

A tensão pelo uso da natureza em atividades culturais pode ser apreendida pelo simbolismo da religião de matriz africana para a qual "a natureza é a casa" das divindades. É explicada pela articulação entre a Determinação Rural (DR) e a Determinação Geoambiental, as quais se vinculam à resistência e a permanência desse uso simbólico-cultural da água a despeito da denúncia de poluição dessas. A Determinação do Planejamento (DP), na síntese dessas determinações, explicita o modelo de desenvolvimento metropolitano orientador da apropriação capitalista da natureza associado ao uso da água mediado pela técnica, onde as fontes públicas e naturais foram alijadas da produção e organização espacial, e abandonadas, apesar de serem amplamente utilizadas.

Poluição afeta fontes sagradas - Líderes de terreiros de Cajazeiras e entorno estão cobrando ao poder público proteção para espaços sagrados. Ontem, eles conseguiram que o secretário municipal da Reparação, Gilmar Santiago, visitasse a Cachoeira de Oxum e um trecho do Rio do Prata. Ambas estão localizadas em trechos remanescentes de Mata Atlântica e passam por um processo de degradação que vai do desmatamento à contaminação por esgotos. [...] "A água dessa cachoeira era limpa há alguns anos. Hoje está desse jeito. Isso dói muito, pois a natureza é a casa das nossas divindades", disse Mãe Ana. [...] A área escolhida por mãe Juscelina é o Loteamento Santo Antônio, onde estão sediados pelo menos oito terreiros. Nessa localidade fica também um trecho do Rio do Prata. "As fossas que são abertas na área acabam contaminando a água", conta a sacerdotisa. (Funke 2005, p. 07). DR; DG; DP

A tensão pelo uso da natureza em atividades culturais pode ser apreendida no uso cultural da água como natureza, como lazer e como um bem natural, em flagrante oposição ao processo de metropolização que, no caso da RMS, foi erigido entendendo que os mananciais inseridos nessa região se constituíam obstáculo ao desenvolvimento urbano e industrial. A Determinação Rural está presente na permanência do uso direto da água como cultura e atividade pesqueira.

A cidade dentro da cidade - janeiro, sol, dia azul. "Vamos descer para Ipitanga?”, sugere José Nascimento, 22, aos amigos. Mas não é a praia perto do Flamengo onde eles vão aproveitar o dia. O destino é a "praia" particular dos moradores de Cajazeiras: com água doce, algas e muito mato em volta, a Barragem de Ipitanga é o programa dos finais de semana e dias de férias, para onde José vai desde os dez anos. "A barragem é nosso piscinão, é o que nos salva. Aqui não tem muito lugar para gente ir, não". O bairro de Cajazeiras nasceu como um conjunto habitacional, há 24 anos. Das fazendas que foram desapropriadas para o projeto (Jaguaripe de Cima, Fazenda Cajazeiras e Fazenda Boa União) veio o nome do bairro. Não demorou para que os prédios fossem cercados de construções informais. No maior bairro de Salvador vivem mais de 600 mil habitantes (mais gente até do que em Feira de Santana). São 18.583 casas populares 
nas 11 Cajazeiras e quatro Fazendas Grandes, que se misturam também com Boca da Mata e Águas Claras [...] (Portugal, 2008, p. 6). DR; DP; DU; DG

A tensão pelo uso da natureza em atividades culturais é também explicada pela Determinação do Planejamento (DP), norteadora da ocupação da área, em 1984, a despeito da presença da barragem, desde 1935, e da importância de conservar a biodiversidade local, em um dos últimos mananciais para abastecer Salvador. Existe uma articulação com a Determinação Geoambiental (DG), pelo descumprimento da lei, o uso do lago da barragem, pelas moradias em seu entorno, proibidas desde sua construção, pelo risco ambiental com a urbanização.

A dimensão Natural indica a presença de um risco próprio das condições naturais de determinados mananciais inseridos na RMS, tais como risco de afogamento nos lagos de barragens e em determinados trechos de rios. Contudo, as dimensões predominantes Cultural e de Subjetividade apontaram que aquele risco foi ignorado pelas pessoas diante da vivência cotidiana que marca suas trajetórias de pesca e os usos recreativos. As dimensões da cultura e da subjetividade não devem ser desprezadas pelo Planejamento, as quais são predominantes na realidade configurando os modos de vida onde a relação direta com as águas é valorizada e mantida.

\section{Conclusões}

As relações entre sociedade e natureza configuram a Região Metropolitana de Salvador como um espaço de intensas disputas pela apropriação das águas doces tendo em vista os usos que atendem ao padrão urbano industrial de desenvolvimento capitalista em detrimento da vida cotidiana em geral das populações locais dos seus municípios e, em especial das populações com identidade sócio-histórica rural, embora seja a região abundante em número de mananciais e volume de água.

A aplicação dos Indicadores Qualitativos de Tensões pelo uso da Água (IQTA) permitiu a congregação de dimensões subjetivas às objetivas da realidade social, em que as águas doces figuram como elemento da natureza em disputa no espaço da metrópole. A sua aplicação deslindou uma dimensão da realidade que emergiu principalmente a partir do suporte teórico e metodológico das noções de rural e ruralidade metropolitana, que no plano teórico nos conduz à superação dicotômica da relação rural-urbana e, no plano empírico, revela-nos a resiliência com a qual o rural se desenvolve e resiste no urbano.

Além disto, o IQTA auxiliou no reconhecimento empírico de dinâmicas próprias do rural em relação com o uso das águas doces, ainda que sob tensão, capazes de revelar potencial para o desenvolvimento humano e para conservação da natureza, já que tais usos reclamam por boas condições ambientais dos mananciais e pela sua conservação. Implica dizer, com isto, que estamos diante dos sinais de um novo padrão civilizatório em que a questão ambiental poderia ser ressignificada no espaço da metrópole como questão rural-urbana, como reivindicação pela natureza não reificada neste espaço.

A despeito disto, constatamos que a dinâmica rural na relação com as águas segue ignorada pelo planejamento metropolitano e pelas políticas públicas, quando não é reduzida em importância ao ser comparada com o modelo civilizatório urbano-industrial, no âmbito da modernidade. Ou seja, ainda que o dado da realidade vivida, revelado nas 
evidências, expressem uma dinâmica rural marcada pelos usos diretos da água, no espaço da metrópole e da sua RM, tal dinâmica é deliberadamente invisibilizada.

A inviabilização do modo de vida rural, revelada pela aplicação do IQTA, é ainda mais violenta quando alcança os sujeitos, sobretudo os mais vulneráveis socioeconomicamente, que buscam se relacionar diretamente com as águas doces e, dessa forma, reafirmar o seu modo de vida através do trabalho, da religiosidade e da cultura.

Além disso, o IQTA, aos explicitar as tensões pelo uso das águas doces, demonstrou a fragilidade socioecodinâmica do modelo civilizatório urbano-industrial ao se apropriar das águas de forma utilitarista, como mercadoria depreciável e prontamente substituída quando o manancial é degradado. Tal fragilidade expõe o aprofundamento da falha metabólica da relação metropolitana com as águas, que a despeito do quadro consolidado de crise da água na atualidade, permanece idealizada como abundante e com possibilidade quase indefinida de substituição permanentemente dos mananciais utilizados para o abastecimento urbano-industrial. Com isto, novos mananciais são apropriados cada vez mais distantes do espaço da RMS, sem a consideração da política de proteção e recuperação dos mananciais existentes, consolidando o espraiamento da questão metropolitana para além dos seus limites físicos.

Por fim, obteve-se uma predominância da tensão pela apropriação da água T-1, principalmente nas áreas de maior demanda por água para usos urbano-industriais. A tensão dos usos da água em atividades culturais foi a menos frequente e confirmou a permanência, contra-hegemônica, da ruralidade no espaço metropolitano. Por sua vez, os Indicadores Qualitativos de Tensões pelo uso da Água (IQTA) podem subsidiar o planejamento contra-hegemônico, de base ambiental e territorial, que valorize a vida daqueles que desejam se desenvolver em relação direta com as águas, e reconheça a relevância da cultura e do território para a cidadania e política.

Conclui-se afirmando o IQTA como metodologia/indicadores qualitativos que carrega potencial interpretativo, mas também de intervenção na perspectiva de planejamento insurgente tendo em vista a dignidade da pessoa humana em sua complexidade.

\section{Agradecimentos}

O presente trabalho foi realizado com apoio da Coordenação de Aperfeiçoamento de Pessoal de Nível Superior - Brasil (CAPES) - Código de Financiamento 001.

\section{Referências}

Acselrad, H. As práticas espaciais e o campo dos conflitos ambientais. In: Acselrad, H. (Org.). Conflitos ambientais no Brasil. Rio de Janeiro: Relume Dumará: Fundação Heinrich Böll, p.13-35, 2004.

Alencar, C. M. M. Potencial interpretativo e instrumental da noção de ruralidade metropolitana. In: Bórguez, L. C. (Org.). Nueva ruralidad enfoques y propuestas para América Latina. México: Centro de Estudios para el Desarrollo Rural Sustentable y la Soberanía Alimentaria, Cámara de Diputados, XIL Legislatura, p. 151-173, 2006. Disponível em: http://www.cedrssa.gob.mx/files/b/8/ 27Nueva_Ruralidad_enfoques_AL.pdf. Acesso em: out. 2019.

Alencar, C. M. M. Campo e Rural na Metrópole: Sinais de um padrão civilizatório. Curitiba: CRV, 2017.

Alencar, C. M. M. Desenvolvimento Rural no Território. 
Revista Brasileira de Planejamento e Desenvolvimento, 8(2), 311-331, 2019. doi: 10.3895/rbpd.v8n2.8324

Alencar, C. M. M.; Moreira, R. J. Campo e cidade metropolitanos: uma noção inteira para pensar o desenvolvimento humano contemporâneo. In: Roberto J. M. (Org.). Identidades sociais: ruralidades no Brasil contemporâneo. Rio de Janeiro: DP\&A, p. 295-316, 2005.

Alencar, C. M. M.; Schweizer, P. J. (Orgs.). Transformações territoriais: de rural a metropolitano. Campinas, São Paulo: Alínea, 2008.

Alvim, R. G. Bases da Ecologia Humana. In: Alvim, R. G; Badiru, A. I; Marques, J. (Org.). Ecologia Humana: uma visão global. Feira de Santana: UEFS, 2014.

Azevedo, E. A. Seca em Matatu. A Tarde, Salvador, 13 abr., p. 2, 2005.

Barbault, R. Ecologia geral: estrutura e funcionamento da biosfera. Petrópolis: Vozes, 2011.

Brasil. Lei Federal $n^{\circ} 9.985$ de 18 de julho de 2000. Regulamenta o art. 225, $\S 1^{\circ}$, incisos I, II, III e VII da Constituição Federal, institui o Sistema Nacional de Unidades de Conservação da Natureza e dá outras providências. Brasília: DOU de 19.7.2000.

Castro, J. E.; Kohan, G. A.; Poma, A.; Ruggerio, C. Territorialidades del agua: conocimiento y acción para construir el futuro que queremos. Ciudad Autónoma de Buenos Aires: Fundación CICCUS; Waterlat-Gobacit, 1. ed., 2019. doi: 10.5281/zenodo.3948431

Castro, J. E. A água (ainda) não é uma mercadoria: aportes para o debate sobre a mercantilização da água. Revista da Universidade Federal de Minas Gerais, 20(2), 190-221, 2016. doi: 10.35699/2316-770X.2013.2697

Castro, J. E. Water governance in the twentieth-first century. Ambiente \& Sociedade, 10(2), 97-118, 2007. doi: 10.1590/S1414-753X2007000200007

Capra, F. O Ponto de mutação. trad. Álvaro Cabral. São Paulo: Cultrix, $1^{\mathrm{a}}$ ed. $31^{\mathrm{a}}$ reimpressão, 2012.

Capra, F; Luisi, P. L. A visão sistêmica da vida: uma concepção unificada e suas implicações filosóficas, políticas, sociais e econômicas. Trad. Mayra T. E; Newton R. E. São
Paulo: Cultrix, 2014.

D'Ambrosio, U. Educação para uma sociedade em transição. São Paulo: Papirus, 1999.

Funke, K. Poluição afeta fontes sagradas. A Tarde, Salvador, 21 mai. p. 7, 2005.

Franco, A. Extração ilegal de areia ameaça o equilíbrio do Rio Joanes-Ipitanga. A Tarde. Salvador, 30 Ago., 2014.

Haesbaert, R. O mito da desterritorialização: do "fim dos territórios" à multiterritorialidade. Rio de Janeiro: Bertrand Brasil, 11 ed., 2004.

Lapuente, R. S. O jornal impresso como fonte de pesquisa: delineamentos metodológicos. In: Anais do Encontro da História de Mídia, Porto Alegre. 3 a 5 de jun., 2015.

Martínez, J. A. Los conflictos ecológico-distributivos y los indicadores de sustentabilidad. Revibec, 1, 21-30, 2004. Disponível em: https://ddd.uab.cat/pub/revibec/revibec a2004v1/revibec_a2004v1a7.pdf. Acesso em: out. 2020.

Mata, L. D. Moradores de Bom Jesus constroem o próprio esgoto. A Tarde. Salvador, 02 mar. 2008.

Porciúncula, D. Tensões territoriais no uso da água em Dias d'Ávila - Bahia. Salvador, Dissertação (Mestrado em Planejamento Territorial e Desenvolvimento Social) UCSAL, 2011.

Porciúncula, D. O fenômeno das águas doces na Região Metropolitana de Salvador: usos, alterações e abandono. Salvador, Tese (Doutorado em Planejamento Territorial e Desenvolvimento Social) - UCSAL, 2017.

Porciúncula, D. C. L da; Alencar, Cristina M. M. Tensões territoriais no uso das águas na Região Metropolitana de Salvador (RMS), Bahia. Revista Política e Planejamento Regional, 6, 150-163, 2019.

Porciúncula, D; Alencar, C. M. M. Desenvolvimento urbano industrial na ruralidade em Dias D’Ávila - Bahia. In: Anais do I Congresso Brasileiro de Organização do Espaço. Rio Claro: UNESP, 5 a 7 out., 2010.

Portugal, M. A cidade dentro da cidade. A Tarde, Salvador, 15 jan., p.8, 2008.

Santos, M. O espaço do cidadão. São Paulo: Edusp, 7 ed., 
2012.

Santos, M. O dinheiro e o Território. In: Santos, M. (Orgs.). Território, territórios: ensaios sobre ordenamento territorial. Rio de Janeiro: Editora Lamparina; p. 13-21, 2007.

Saquet, M. A. As diferentes abordagens do território e a apreensão do movimento e da (i) materialidade. Geosul, 22(43), 55-76, 2007. Disponível em: https://periodicos.ufsc. br/index.php/geosul/article/view/12646/11806.

Siqueira, M. da P. S. Urbanização desigual e desigualdade nacional: um descaminho no processo do desenvolvimento brasileiro. Dimensões, 25, 215-234, 2010. Disponível em: https://periodicos.ufes.br/dimensoes/article
Souza, M. L. de. Os conceitos fundamentais da pesquisa sócio-espacial. Rio de Janeiro: Bertrand Brasil, 2013.

Toledo, V. M. El metabolismo social: una nueva teoría socioecológica. Relaciones, 34 (136), p. 41-71, 2013. Disponível em: http://www.scielo.org.mx/pdf/rz/v34n136/ v34n136a4.pdf.

Veríssimo, C. F. de S. Conflitos emergentes na gestão das águas. Lisboa, Dissertação (Mestrado em Engenharia e Gestão de Água) - FCT, 2010. 